\title{
Fluoridation of water supplies and cancer mortality I: A search for an effect in the UK on risk of death from cancer
}

\author{
PAULA COOK-MOZAFFARI \\ From the Department of Community Medicine and General Practice (MRC External Staff), University ofOxford
}

\author{
LAK BULUSU \\ From the Office of Population Censuses and Surveys, London
}

\author{
RICHARD DOLL \\ From the ICRF Cancer Epidemiology and Clinical Trials Unit, University of Oxford
}

\begin{abstract}
Claims that the mortality from cancer has been increased in urban populations as a result of the fluoridation of water supplies have been given publicity in the press and on the radio and television, and questions have consequently been asked in Parliament with a view to stopping plans for further fluoridation. These.claims have been based on an analysis of the trend in cancer mortality rates in American towns by Yiamouyiannis and Burk ${ }^{1-3}$ and more recently on an analysis of crude cancer mortality in two British towns-Birmingham, where the water supply was fluoridated in October 1964, and Manchester, where there has been no fluoridation. ${ }^{45}$ The differences observed in the mortality rates in the American cities have been examined by representatives of the Royal Statistical Society in this country ${ }^{6}$ and by many other statisticians, epidemiologists, and cancer research workers in Britain, New Zealand and the United States of America ${ }^{7-10}$ All agree that the differences observed are explicable by demographic factors, that is, by differential changes in the age, sex, and ethnic distributions of the city populations, and that there is no evidence to suggest that fluoridation has had any harmful effect.
\end{abstract}

The present paper examines the trends in mortality from cancer in Birmingham and in six other cities.

\section{Materials and methods}

The numbers of cancer deaths, by sex and by type of cancer, for the periods 1959-63, 1969-73, and 1974-8 have been obtained for Birmingham and for six other cities in England and Wales (London, Manchester, Liverpool, Sheffield, Leeds, and Bristol) which had populations nearest in size to that of Birmingham at the start of the study period. These were the only seven cities which, in the 1961 national census, had populations of over 400000 and all except Birmingham have water supplies which have not been fluoridated.* The cancer data were taken from the Registrar General's area mortality tables and from the annual volumes of his Statistical Review of England and Wales. ${ }^{11-14}$ Population data by sex and age were taken from the county volumes of the 1961 and 1971 national censuses, and population estimates by sex and age for individual years from 1974 to 1978 were obtained from the Office of Population Censuses and Surveys (OPCS) which is able to provide such information for all the post-1974 districts on request.

Age-standardised mortality ratios (SMRs ${ }^{15}$ ), obtained by dividing the observed numbers of deaths by the expected numbers, have been calculated for each sex, for each of the seven cities, and for England and Wales as a whole, for each time period. The SMRs have been calculated for 'all malignant neoplasms' and for the 12 individual types of cancer for which data are available in the published reports. $\dagger$ The sex- and age-specific death rates used for the estimation of the expected values at each period were the geometric meanst广 of the average annual rates for England and Wales for 1959-63 and for 1969-73 for men and women at ages $0-4$ and for each 10-year age group from 5-14 up to 75-84, and the age group

*With the exception of Leeds, where $5.6 \%$ of the population have received fluoridated water since 1967.

+Buccal cavity and pharnyx; oesophagus; stomach; intestine and rectum; larynx; lung and bronchus; breast; cervix uteri; other uterus; protate; bladder; and leukaemia.

†The geometric mean of the two sets of age-specific rates was used on the assumption of an equal rate of change from year to year. Subsequent experimental substitution of arithmetic means made only very slight difference to the average age-specific rates and virtually no difference to the SMRs calculated from this standard. 
85 and over. The expected values for 1959-63 and 1969-73 were calculated using the mid-point populations for 1961 and 1971. Those for 1974-8 were derived from the populations for each year separately and the expected and observed values were summed over the five-year period, before the calculation of ratios: The SMRs have been converted to standardised rates by multiplying by the age-standardised death rates for England and Wales for men and women (derived from the mean national age-specific rates, described above, applied to Segi's world standard population ${ }^{16}$ ).

In calculating disease rates in England and Wales it is customary to use 'resident' populations in which people have been reallocated to their areas of residence from the areas in which they were staying on the night of census enumeration. 'Resident' populations with a sufficiently fine breakdown by age are not available for 1961 and so, in order to achieve comparability, the populations enumerated at the time of the census have been used for both 1961 and 1971. The population estimates provided by the OPCS for the years 1974-8 were 'resident' populations, and these have been adjusted to estimates of 'enumerated' populations by multiplying by factors derived from the 1971 'resident' and 'enumerated' populations for each city." The rates obtained for each city for 1974-8 by using the estimates for both the 'resident' and the 'enumerated' populations are set out in Table 1. There is a very slight loss of comparability between cities at any point in time by using the 'enumerated' rather than the 'resident' populations, but the comparisonsover time both within and between cities are preserved by using the same estimates of population for each period (given the assumption, that is, that the 'resident' and 'enumerated' populations within each city stood in constant relationship to each other over the three periods).

A more serious problem of comparability over time arises because of boundary changes in the cities under investigation. Details of the changes from 1959 to 1973 have been taken from the annual volumes of the Registrar General's statistical review, and information on the 1974 reorganisation of local authority areas was obtained from the Atlas of Business in Britain. ${ }^{17}$ London was expanded in 1965 but, because both cancer and population data are published for individual London boroughs, it has been possible to study at each period the composite

-That is, the ratios of 'enumerated' to 'resident' populations in 1971 for the broad age groups. $0-14,15-44,45-64$, and $65+$ for each sex were used as adjusting factors for the age groups within them, that were used for the calculation of the cancer death rates. This adjustment was preferred to the alternative of converting the 1961 'enumerated' populations to 'resident' populations, because of the advantage it gave of using a breakdown of the populations up to age $85+$ for age-standardisation.
Table 1 Effect of changing from 'resident' to 'enumerated' populations for the calculation of age-standardised mortality rates

\begin{tabular}{|c|c|c|c|c|}
\hline & \multicolumn{4}{|c|}{$\begin{array}{l}\text { Average annual }(1974-8) \text { age-standardised } \\
\text { death rates per } 100000 \text { (estimated from } \\
\text { SMRs) using: }\end{array}$} \\
\hline & \multicolumn{2}{|c|}{$\begin{array}{l}\text { 'Resident' } \\
\text { populations }\end{array}$} & \multicolumn{2}{|c|}{$\begin{array}{l}\text { 'Enumerated' } \\
\text { populations }\end{array}$} \\
\hline & Men & Women & Men & Women \\
\hline Birmingham & $213 \cdot 2$ & 129.8 & 213.5 & $130 \cdot 2$ \\
\hline London & 209.6 & 127.9 & 209.6 & $128 \cdot 5$ \\
\hline Bristol & 196.5 & 115.9 & 197.0 & $116 \cdot 3$ \\
\hline Liverpool & 249.9 & $143 \cdot 3$ & 250.0 & 144.0 \\
\hline Manchester & $235 \cdot 5$ & $136 \cdot 3$ & 235.5 & 136.7 \\
\hline Sheffield & $207 \cdot 5$ & $127 \cdot 1$ & 207.0 & $128 \cdot 1$ \\
\hline Leeds & 194.4 & 124.7 & 195.1 & $125 \cdot 6$ \\
\hline
\end{tabular}

area known in 1959 as the 'London Administrative County'. In 1974 Birmingham was expanded to include Sutton Coldfield municipal borough (MB), Manchester to include a part of Bucklow rural district (RD), Sheffield to include Stonesbridge urban district (UD) and Wortley rural district; and Leeds to include seven complete and three partial other local authority areas.* The cities themselves, which had formerly been county boroughs (CB), were now termed metropolitan districts (MD). To preserve comparability over time, two sets of cancer death rates for the period 1969-73 have been estimated for the four cities which had boundary changes in 1974 : one for the county boroughs as defined in 1971 (for comparison with the period 1959-63) and one for a summation of the areas which became the metropolitan districts in 1974 (for comparison with the period 1974-8). Populations for the additional local authority areas were taken from the 1971 census; the number of cancer deaths were provided by the OPCS. Where only part of a local authority area had been included in the new metropolitan districts, half the population and half the cancer deaths for that area were added in the total summation.t

Minor changes in the population of Birmingham and of Bristol took place between 1959 and 1973 as a result of boundary changes, and Sheffield was expanded by approximately $8.5 \%$ of its population in 1967. No allowance has been made for these changes because they were made at the level of parishes and

-Aireborough UD; Garforth UD; Horsforth UD; Morley MB; Otley UD; Pudsey MB; Rothwell UD; a part of Tadcaster RD; most of Wharfedale RD (all included); and a part of Wetherby RD.

†At the time of calculation of these rates, the author responsible (P. C-M) was unaware of the OPCS publication which gives the exact proportion of each old local authority area which went to make up the new districts created in 1974 However, use of the exact proportions (instead of the 50\% approximation described above) would cause negligible changes in the rates for the summed areas. 
parts of parishes and no cancer or population data exist which would permit suitable adjustment. The changes in Birmingham and Bristol were too small to have had an appreciable effect. They will have had an effect on the figures for Sheffield, which are fully comparable only for the last two periods.

In 1972 a change of classification was introduced by the OPCS into their published annual mortality tables, in that foreigners dying in England and Wales (including Scots) were no longer classified under their places of death, as had formerly been the custom in the tables on mortality by place of residence. In order to make the $1969-73$ area mortality tables comparable with those for previous years, foreigners dying in England and Wales in 1972 and 1973 were reallocated to their places of death, in keeping with the former practice. The figures used here for 1974-8 do not include foreign deaths. There were 268 such deaths in the London area, as defined in the present paper, in 1972 and 1973 (from comparison of the mortality tables published annually by the OPCS and the 1969-73 area mortality tables which have the reallocated figures). These 268 deaths in two years would give approximately 670 deaths over the full five years, a decrease of $1.7 \%$ from the 38812 deaths recorded in the area mortality tables for the London area. This reduces somewhat the observed decreases for London between 1969-73 and 1974-8 shown in Tables $2 a$ and $2 b(-7 \cdot 7 \%$ for men and $-4.3 \%$ for women for all malignant neoplasms). For the other towns the new system of classification has a negligible effect, the reduction being of the order of $0.25 \%$ or less.

The estimated age-standardised death rates that have been derived by the methods described above are presented in Tables $2 a$ and $2 b$ together with the percentage changes in rate that occurred between each period. The probability that the degree of observed variation could have occurred by chance is indicated, for each sex, for the two changes over time within each city and for the changes over time in each of the other six cities relative to the changes which have occurred in Birmingham. (See footnote to Table 2b).

The average values for both sexes combined and for the non-fluoridated cities were calculated without weighting, on the assumption that the variation in rates observed between sexes and between cities represents not merely random fluctuation but the interplay of different causal factors. Consequently no tests of significance are applied to them. The averages for the cities other than Birmingham have been calculated with and without London. Use of London for comparison may be inappropriate because of its position as the capital city where so

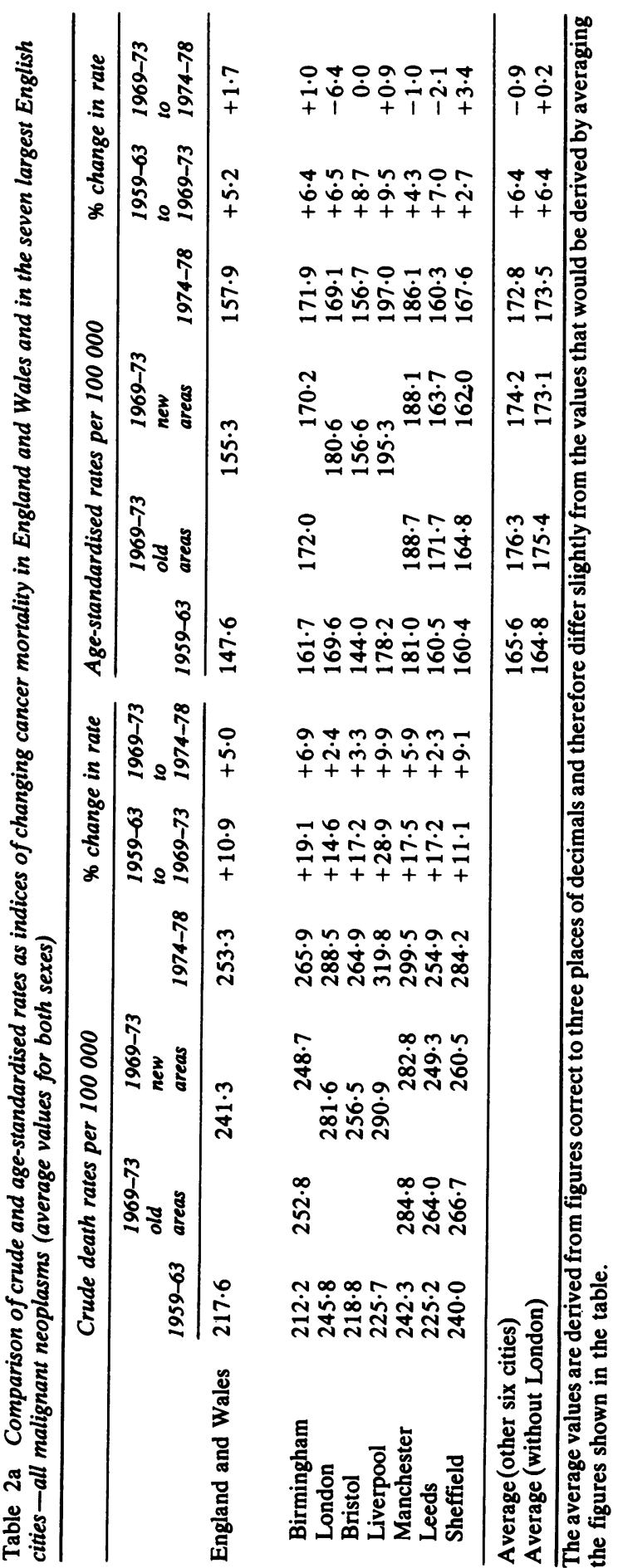



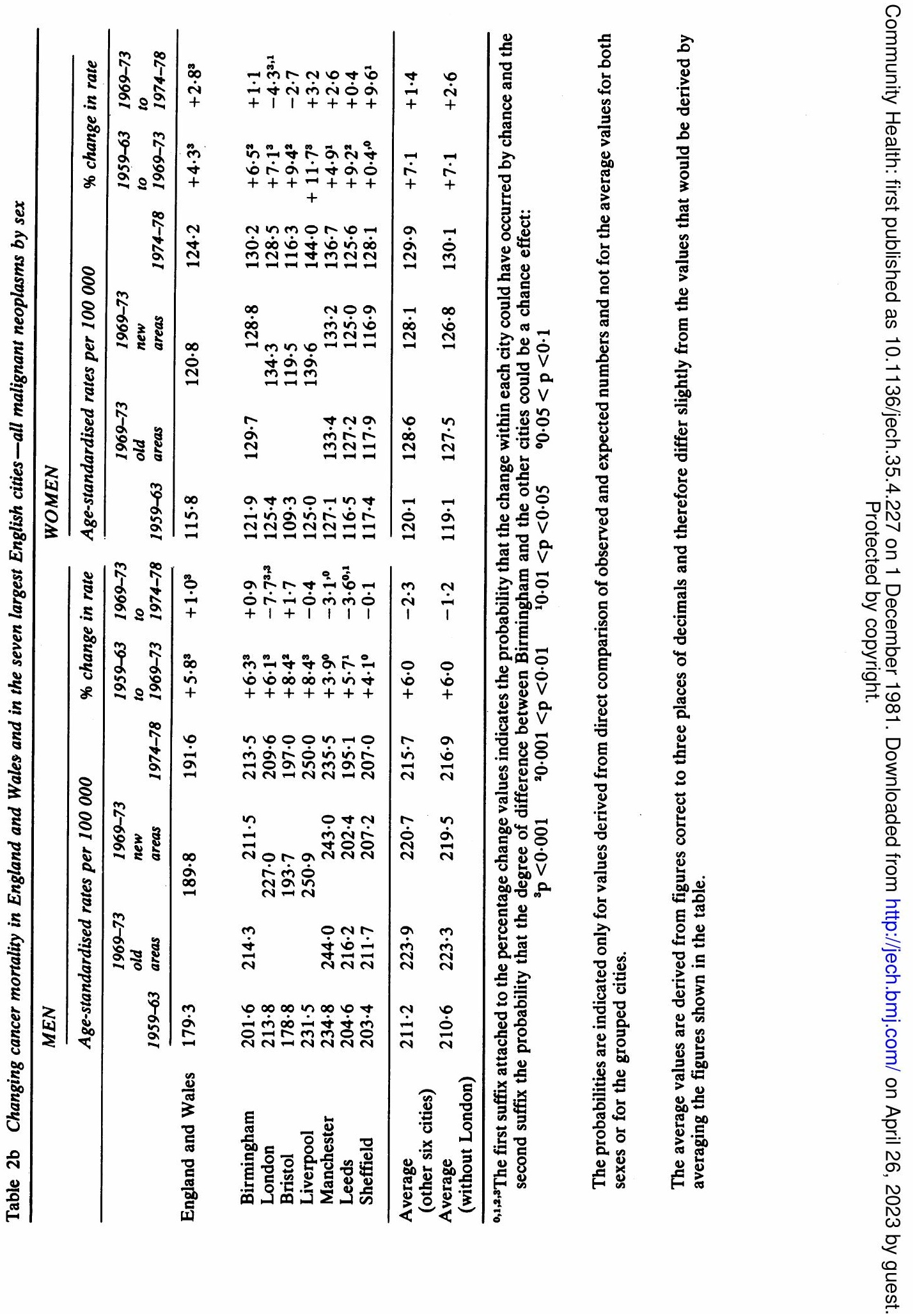
many specialist medical services are concentrated and because it is so much larger than the other cities.

There has also been a higher rate of migration into central London than has occurred in the other cities. (In $1971,15 \cdot 7 \%$ of the age group most affected by cancer, those aged $45+$, had moved into London in the five years before the census compared with $4.5 \%$ in Birmingham). The other cities had inward migration rates similar to that for Birmingham and, whereas a dilution effect of around $5 \%$ is unlikely to affect the comparisons between Birmingham and the other provincial cities, the higher proportion for London could have had a noticeable effect on the mortality rates which would otherwise have been observed there.

Crude death rates, in which total deaths are divided by total population without adjustment for variation in age structure, have also been calculated, because these were the type of rate on which Burk based his original claim of a sharp increase in cancer mortality in Birmingham following fluoridation. ${ }^{4}$ The average crude values for both sexes and the associated percentage changes are shown in Table 2 alongside the age-standardised rates. The comparison shows the extent to which an artificial appearance of a large increase can be created by failing to take account of changes in the age distribution of the population, even over such short periods as five or 10 years. It also demonstrates how use of the crude rates as an index of cancer mortality alters the relative position of the seven cities.

\section{Results}

Between 1959-63 and 1969-73 in Birmingham the average age-standardised death rate for both sexes combined for all malignant neoplasms (the cancer death rate) increased by $6.4 \%$ (Table $2 a$ ). This increase was almost identical to the average increase observed in the other six cities (6.5\%) and was centrally placed within the range of values observed in the other six cities (from $2.7 \%$ in Sheffield to $9.5 \%$ in Liverpool). Five of the seven cities saw an increase in the cancer death rate over this period which was greater than that observed in England and Wales as a whole $(5 \cdot 2 \%)$.

Between 1969-73 and 1974-8 in Birmingham the cancer death rate increased by $1.0 \%$. The other six cities experienced on average a decrease of $0.9 \%$ and only Sheffield saw an increase that was greater (3.4\%) than that observed in Birmingham. Between these later periods, however, the increase in Birmingham was less than that in the country as a whole (increase in England and Wales, 1.7\%).

From Table $2 b$ it is clear that the difference between Birmingham and the other six cities between
1969-73 and 1974-8 is due to changes in the cancer death rates for men and, in particular, to the changes in Manchester, Leeds, and London, where decreases of from $3 \%$ to $8 \%$ were observed. For women the increase of $1.1 \%$ in the cancer death rate which took place in Birmingham was less than the average increase in the other six cities, while Liverpool, Manchester, and Sheffield all experienced increases in rate larger than that in Birmingham. Neither the increase of $0.9 \%$ for men nor that of $1.1 \%$ for women, which were seen between the later two periods in Birmingham, was statistically significant ( $p>0.05$ ), and only the decreases in London of $7.7 \%$ for men and $4.3 \%$ for women and the decrease of $3.6 \%$ for men in Leeds differed significantly from the changes observed in Birmingham.

When the changing rates for individual types of cancer were considered there was no one type for which there was a rate of increase in Birmingham over both periods (or even over one period), and for both sexes, that was more extreme than the changes observed in the other six cities. Nor were there continued and more extreme increases over time for cancers that affect only one sex. The details of rates and rates of change for individual types of cancer have, therefore, not been tabulated in the present paper but are available on request.

\section{Conclusion}

Examination of the trend in mortality for cancer in the seven cities in England and Wales with populations of over $400000^{*}$ and in England and Wales as a whole between 1959-63 and 1974-8 provides no reason to suppose that any unique factor, such as fluoridation of the water supplies, has affected the death rate for cancer in Birmingham since 1964 .

*In 1961.

Reprints from Ms. P. Cook-Mozaffari, Medical Research Council External Staff, Department of Community Medicine and General Practice, University of Oxford, Oxford OX1 3QG.

\section{References}

${ }^{1}$ Burk D, Yiamouyiannis J. Letter (21 July). Congressional Record 1975; 191: H 7172-6. Washington DC: US Government Printing Office.

${ }^{2}$ Yiamouyiannis J, Burk D. Letter (16 December). Congressional Record 1975; 191: H 12731-4. Washington DC: US Government Printing Office.

${ }^{3}$ Yiamouyiannis J, Burk D. Fluoridation and cancer: age dependence of cancer mortality related to artificial fluoridation. Fluoride 1977; 10: 102-23. 
4Burk D. An open letter to Sir Emmanuel Kaye, CBE. 22 October 1979.

${ }^{5}$ Burk D. Letter to an official at the Department of Health and Social Security, London. 5 November 1979.

- Oldham PD, Newell DJ. Fluoridation of water supplies and cancer-a possible association. Appl Stat 1977; 26: 125-35.

${ }^{7}$ Hoover RN, McKay FW, Fraumeni JF. Fluoridated drinking water and the occurrence of cancer. $J$ Natl Cancer Inst 1976; 57: 757-68.

- Doll R, Kinlen L. Fluoridation of water and cancer mortality in the USA. Lancet 1977; i: 1300-2.

${ }^{9}$ Taves DR. Claims of harm from fluoridation. In: Continuing evaluation of the use of fluorides. Johansson E, Taves DR, Olsen TO, eds. Boulder, Colorado: Westview Press, 1979.

${ }^{10}$ Smith AH. An examination of the relationship between fluoridation of water and cancer mortality in 20 large US cities. New Zealand Med J 1980; 91: 413-6.

${ }^{1}$ Registrar General. Decennial supplement, England and Wales, 1961. Area mortality tables. London: HMSO, 1967.
${ }^{12}$ Office of Population Censuses and Surveys. The Registrar General's decennial supplement, England and Wales, 1971. Area mortality tables. London: OPCS, 1979 (microfiche).

${ }^{13}$ Office of Population Censuses and Surveys. Mortality statistics-area. Review of the Registrar General on deaths by area of usual residence in England and Wales (for the years 1974, 1975, 1976 and 1977). London: OPCS, 1976, 1977, 1978, 1979.

${ }^{14}$ Registrar General. Statistical review of England and Wales part I, tables, medical (for the years 1959 to 1973). London: HMSO, 1960-75.

${ }^{15}$ Bradford Hill A. Principles of medical statistics. 4th edn. London: Lancet 1948.

${ }^{16}$ UICC. Cancer incidence in five continents, volume $I$. Doll R, Payne P, Waterhouse J, eds. Berlin: Springer, 1966.

${ }^{17}$ Diamond D, Edwards R, eds. Business in Britain: a Phillip management planning atlas. London: George Phillip, 1975. 